\title{
Perceived sensory quality of unpolished pigmented and milled white rices
}

by Juemanee, A., Kijroongrojana, K., Meenune, M. and Posri, W.

Copyright, Publisher and Additional Information: This is the author accepted manuscript. The final published version (version of record) is available online via Emerald Publishing.

Please refer to any applicable terms of use of the publisher.

DOI: https://doi.org/10.1108/BFJ-01-2017-0032 


\section{Perceived sensory quality of unpolished pigmented and milled white rices}

\begin{tabular}{|r|l|}
\hline Journal: & British Food Journal \\
\hline Manuscript ID & BFJ-01-2017-0032.R2 \\
\hline Manuscript Type: & Research Paper \\
\hline Keywords: & $\begin{array}{l}\text { Unpolished rice, Brown rice, Pigmented rice, Sensory evaluation, Flash } \\
\text { Profile, Familiarity }\end{array}$ \\
\hline \multicolumn{2}{|c}{} \\
\hline
\end{tabular}




\section{Introduction}

The UK represents a growing market for rice, with $80 \%$ of the population reporting rice consumption (Schenker, 2012). The UK imports approximately 677,600 tons of rice on average per year of which 53,452 tons is comprised of Thai rice (International Trade Centre, 2014). Unpolished rice, also known as whole grain rice, attained rapid sales growth between 2013 and 2015 in the UK, partly influenced by the perception among UK rice eaters that whole grain rice is healthier than milled or white rice (Mintel, 2016). Unpolished pigmented rice is rice that has had its hard husk removed, but that remains unpolished and therefore retains the bran layer and the germ. This is also known as 'husked', 'brown' or 'whole grain' rice (European Commission $[E C], 2016)$. Since unpolished rice retains the rice bran layer and the germ, it contains more fibre and nutrients than polished rice, which also has implications for cooking time and shelf life. Presence of bran layer in unpolished rice affects the quality of the cooked rice, leading in particular to harder texture and longer cooking time when compared to white rice (Kushwaha, 2016). The bran layer and the endosperm (rice kernel) of some rice cultivars contains natural pigment ranging from various shades of light red to dark purple colours, leading to the description of such rice as 'pigmented' rice. This pigment in rice is formed by deposits of anthocyanins (Huang et al., 2016) and is reported to be a potent and viable source of antioxidants (Lui et al., 2015). In addition, vitamins, minerals, dietary fibre, protein and several nutraceutical contents in pigmented rice are more abundant compared to white rice (Sumczynski et al., 2015).

The perceptions of rice quality vary from country to country and even between regions within a country depending upon cooking methods, rice in the context of meal combination, familiarity and marketing of the rice. Suwannaporn and Linnemann (2008) suggested that majority of consumers in European countries and the United States (US), have developed familiarity, and hence their preferences towards longgrain rice. Supakornchuwong and Suwannaporn (2012) further noted that long-grain rice gained favour amongst European consumers partly due to the influence of marketing campaigns run by the leading American rice brand that emerged in the European market in the 70s. In the UK, historically the rice claimed to have first entered the UK was American rice during 1775-1783 (The Rice Association, 2017). Basmati rice began to be used in savoury dishes in the $18^{\text {th }}$ century as influenced by British traders who returned from India (Renton, 2013). More recently, Basmati rice has gained a substantial consumer base and sales volume in the UK, influenced by the NPD and marketing strategies of UK-based rice companies such as Veetee Rice Ltd and Tilda (acquired by the American company Hain Daniels Group in 2014) (Chaudhry and Crick, 2005; Renton 2013; Mintel, 2016).

Among the well-known indica-type rices consumed in European countries, Indian Basmati rice presents superior quality in terms of fragrant odours, softness and 
73 light fluffy texture due to its extra-long superfine slender grains and length-wise

74 elongation with least breadth-wise swelling on cooking and tenderness of cooked rice 75 (Bhattacharjee et al., 2002). The Thai jasmine rice presents distinct flavour and odour 76 within a similar price range to Basmati rice, but is not as popular. This is perhaps due 77 to its textural difference arising from Jasmine rice's soft, moist and slightly sticky 78 texture (Suwannaporn et al., 2008; Supakornchuwong and Suwannaporn, 2012; CBI, 79 2016). Thai consumers, however, perceive white colour and sticky cooked Jasmine 80 rice to be of good quality (Kormonchai et al., 2010). The above literature provides an 81 overview of diversity in sensory perceived quality of rice using exemplars Basmati 82 and Thai jasmine rices consumed in our two study countries.

83 In recent years, there has been much interest expressed in nutritional aspects 84 of Thai pigmented rice varieties, mainly because of their high antioxidative properties 85 (Pramai and Jiamyangyuen, 2016). Thus Thailand, as one of the world's top rice 86 exporters, has high potential to boost the global market for Thai Unpolished 87 Pigmented Rice (TUPR). Understanding consumer perceptions of such new products 88 in export markets, and how these perceptions and their drivers differ from those in the 89 more familiar home markets is likely to be of significant practical interest to the Thai 90 rice sector.

There is in particular a lack of insight into how sensory quality of the TUPR is perceived by consumers unfamiliar with the product in countries such as the UK, in comparison to sensory perception under conditions of familiarity. This cross-cultural study on sensory descriptive analysis was thus designed as a comparative study between the UK and Thailand. Furthermore, sensory descriptors generated by the study provide information to guide TUPR positioning with respect to product uniqueness and further development that may be required.

This study fills this gap in knowledge for further TUPR development by firstly using focus groups to gain an overview of UK consumer attitudes towards purchasing, cooking and consuming various commercial rice varieties, including familiar milled white rice types such as American long grain and Basmati rice. The information gained from UK Focus Groups was then fed into the design of Flash 103 Profiling (FP) in the next stage. The results from the Focus Groups and Flash Profiles 104 were used together to generate insight on how lack of familiarity with rice types may 105 influence consumer reactions, and could be used to inform export product 106 development strategies for TUPR.

\section{Materials and Methods}

111 2.1.1 Focus group methodological background

112 Consumer opinions guide sensory scientists to focus on key attributes that can 113 subsequently be used in descriptive analysis or quantitative evaluation. Focus Group 
114 Discussion (FGD) is one of the methods frequently used in sensory evaluation to 115 investigate the perceptions of a specific group of consumers (Lawless and Heymann, 116 2010; Edgar et al., 2012; Boquin et al., 2014). Although focus group methodologies 117 are commonly used across disciplines, procedures can vary in practice. Casey and 118 Krueger (2000) suggest a group comprised of six to nine participants, with at least 119 three groups convened to balance out idiosyncrasies among groups. The participants 120 should have a degree of similarity to encourage comfortable discussions, but should 121 not know each other, in order to gain a wide range of honest and spontaneous 122 responses (Rabiee, 2004).

123

\subsubsection{Focus group methods}

In order to explore consumption preferences regarding milled and unpolished

126 rice, and attitudes towards preparing, cooking and consuming unpolished pigmented 127 rice among the British, a total of 4 focus groups comprising thirty-two UK consumers 128 were recruited from a sensory panellist database compiled in the UK Midlands area 129 (although the study was conducted in the Midlands area of England and therefore a 130 high proportion of the subjects were likely English, we refer to 'British' subjects 131 throughout). Recruitment criteria were set to reflect different lifestyles of students and 132 working parents and rice cooking frequencies (rarely versus regularly), resulting in 133 two groups comprised of household food providers (age 38-55) and leaving-the-nest 134 bachelors (age 18-24) of both genders. The group discussions were held at an 135 academic institution equipped with sensory evaluation, kitchen and conference space 136 facilities.

137 Thus each discussion group was age-specific, but had a balance of both 138 genders and different rice cooking frequencies in order to generate dynamic discussions within groups. The discussion guidelines focused on rice consumption habits including buying, cooking and eating habits, and perceived sensory characteristics of Thai unpolished pigmented rice in comparison to the other mainstream rice varieties. Ethical consent was obtained from the lead author's institution. Discussions were recorded by digital audio recorders after obtaining permission from the participants. The first stage of discussion centred on rice consumption habits, followed by discussion of rice grain buying factors and perceived cooked rice quality.

- Stage 1: Factors influencing rice purchase and consumption

Five types of rice grain products from UK markets, Basmati rice, unpolished Basmati rice, Thai Jasmine rice, red Camargue mixed with wild rice, Arborio/Risotto rice were used in the FGD, capturing a broad range of popular rice and pigmented rice

152 (MNS, known as 'dark jasmine', a Thai pigmented rice sold in local markets and with 153 commercial potential arising from its high anthocyanin and fibre contents) was 
154 included. These six rice types were presented to the groups in original commercial 155 packages of $500 \mathrm{~g}$ and $1 \mathrm{~kg}$ to provide variation in buying portion. The samples were also served in individual plastic cups with lids for individual consideration of the key drivers of their rice grain purchasing decision. Participants were able to visually examine the packaging and labelling of the rice as well as to explore rice grain characteristics.

- Stage 2: Perceived quality indicators of cooked rice

Seven cooked rice samples, including 4 Ready-To-Eat (RTE) branded rice products (Waitrose Basmati Pilau Rice, Tilda brown Basmati rice, Uncle Ben's long grain rice, Waitrose Thai Sticky Rice) were warmed up as instructed by the manufacturers. The other three rice grain samples, including Jasmine rice (Laila brand imported from Thailand and sold in Tesco supermarket) and two research samples of MNS unpolished pigmented rice were included and cooked in order to explore the effects of cooking methods by microwave. The research samples were cooked using two different rice to water ratios of 1:2 and 1:3 using a microwave cooking method modified from Khatoon and Prakash (2007) and Li et al. (2014). All samples were served at room temperature $\left(20-25^{\circ} \mathrm{C}\right)$ to comply with temperature control guidance for food kept for service (based on Guidance on Temperature Control Legislation in the United Kingdom (FSA, 2016)). The serving size was 10 grams each in 2-oz plastic cups with lids. These cooked samples were used to gain key sensory attributes related to the group's perceived quality of cooked rice. The data obtained from each stage of all groups were transcribed, indexed and analysed. Results relevant to cooking methods and preferred sensory quality were input into the design of the samples subsequently used in the Flash Profiling stage.

\subsection{Sensory descriptive analysis - Flash Profiling method}

\subsubsection{Flash Profiling - methodological background}

184

185

186

187

188

189

Flash Profiling (FP) was initially developed by Shifferman in 2002 (Valentin et al., 2012) and has been applied to gain consumer insights in food products ranging from jam to dairy products, baked products, and wine. FP pinpoints similarities and dissimilarities between food products from the consumer's point of view, enabling researchers to explore the effects of variations in raw materials or processes, to gain insights for product and market development, and to understand the link between product sensorial characteristics and consumer reaction. (Dehlholm et al., 2012; Varela and Ares, 2012).

FP is an attractive alternative method to rapidly describe product sensory positioning. It involves panellists generating their own lists of attributes and then ranking samples based on those attributes. Results generated by FP have been compared with results from conventional sensory Descriptive Analysis and it has been found that this rapid method presents discriminating results that are consistent with 
195 results from conventional profiling, but with a large time saving (Valentin et al., 196 2012). In previous applications, products have typically been judged either by 6-12 197 skilled/ experienced panellists or 20-40 consumers.

198 2.2.2 Flash Profiling Methods

199 In this application, eleven UK rice FP panellists were recruited from a 200 panellist database drawn from those who consumed rice at least once a week, were 201 responsible for cooking, and were aged between 18 and 55 years. Thirteen Thai rice 202 FP panellists were recruited from a Thai panellist database based on similar 203 recruitment criteria. The panellists, both Britons and Thais, took 60-90 minutes for 204 FP ranking tasks per replication, with 3 replications. Each FP replication was tested 205 on a different day, for 3 consecutive days. The sequence of assessment was odour, 206 texture, aftertaste, flavour and appearance respectively, specified to increase the ease 207 of evaluation after the pre-trial session. Ten rice samples were tested with individual 208 attribute lists ranging from 25 to 43 attributes. The UK FP data were collected via 209 sensory computerised software Compusense ${ }^{\circledR}$ five, with the option of tied ranks 210 allowed. The same questionnaire and instructions were applied to collect Thai FP 211 data.

\section{$212 \quad$ 2.2.3 Flash profiling - Samples and cooking protocols}

213

214

215

216

217

218

219

220

221

222

223

224

225

226

227

228

229

230

231

232

The Thai and British panels each analysed three replicates of 10 rice samples, with the sample sets in the two countries based on the same raw material batches and cooked using the same specific sample preparation protocols. The sample preparation took place at the kitchen facilities of the British and Thai Universities leading this project. For each FP panel, ten cooked rice samples were prepared from 6 rice grain products, consisting of 4 Thai unpolished pigmented rices (a dark pigmented MNS (also known as black Jasmine), a registered crossbred fragrant rice HNU, the first geographic indicated Thai rice with red pigment SYP, and a deep intense purple glutinous rice NLL with low glycaemic index), and two milled rice products commercially sold in the UK market (Jasmine-Laila brand and Basmati-Tilda brand). Each sample consisted of 250 grams of rice grain, rinsed twice with $35^{\circ} \mathrm{C}$ filtered water. The cooking procedures represented three rice cooking methods modified based on a) feedback from the focus groups on sensory attributes of MNS cooked samples in comparison with others, b) referenced food industry protocols (Khatoon and Prakash, 2007; Li et al., 2014), c) global household cooking practices (Lakshmi et $a l ., 2007)$, and d) inputs an on-going pre-treatment rice research project. The pictures of the ten rice samples used in FPs are shown in Figure 1.

The first cooking method involved microwave cooking to approach convenience cooking, using four research samples of Thai unpolished pigmented rice (labelled NLL, MNS, HNU and SYP) harvested in Thailand. 
233

234

235

236

237

238

239

240

241

242

243

244

245

246

247

248

249

250

251

252

253

254

255

256

257

258

259

260

261

262

263

264

265

266

267

268

269

The second involved using a rice cooker to mimic Asian rice cooking methods, with 2 UK commercial milled rice grains (Jasmine (J) and Basmati (B)) and a research sample SYP (ERC) which is an unpolished Jasmine red pigmented rice.

The third method employed pressure cooking on three samples comprising mixtures of Thai unpolished pigmented rice and milled rice (1:1 ratio) (labelled NLLJ, HNU-J and HNU-B). These three samples were included for exploration purposes, to find out how perceived sensory intensities vary between unpolished (MNS, HNU and NLL), milled ( $\mathrm{J}$ and B) rices and mixtures of these. Since unpolished pigmented rice requires a different cooking time and water ratio than for milled rice, an electric pressure cooking method was applied to ensure mixtures would be completely cooked.

After each rice sample was cooked and left (at $25{ }^{\circ} \mathrm{C}$ for 10 minutes), it was then packed in an insulated polyethylene terephthalate container and wrapped with aluminium foil to retain the moisture. The packed samples were kept at $25{ }^{\circ} \mathrm{C}$ for $1-2$ hours prior to the FP analysis. The serving samples comprised of ten grams of cooked rice each, temperature within the range of 18 to $25{ }^{\circ} \mathrm{C}$ and served within 2 hours after cooking to ensure food safety. The samples were served in 2-oz plastic cups with the lid on.

\subsection{Data analysis}

Data obtained from the focus group discussions were recorded, transcribed, coded and interpreted. Prominent themes emerging from the conversations were picked out from the responses verbatim. A list of words associated with individual sample perception was employed to compare the derived information within and between cases (Casey and Kreuger, 2000; Rabiee, 2004).

FP rank data from each panellist were analysed using Generalised Procrustean Analysis (GPA) with XLSTAT 2016 software (Addinsoft, 2016; XLSTAT, 2016). GPA is a multivariate analysis technique that uses an iterative algorithm and scaling adjustment to transform individual assessor ratings into a display of consensus product maps (Valentin et al., 2012). RV coefficient test is applied to test vector correlation of each FP GPA data set using XLSTAT 2016 (Addinsoft, 2016; XLSTAT, 2016).

\section{Results and Discussion}




\subsection{Focus group results}

During the first Focus Group sessions, an understanding of rice grain perception was gained and the sensory quality considered in cooked rice was explored using examples of both milled and unpolished rices. Key findings from the focus groups (Figure 2) are discussed accordingly.

\subsubsection{Factors influencing rice consumption and purchase}

UK participants from both age groups for whom rice was already a regular part of their diets had switched to consuming rice in place of potato or pasta about 2-3 times per week. Young adults (19-24 years of age) in particular stated the reasons for such replacement was the cheaper and more fulfilling nature of rice compared to potatoes, with particular reference to the case of American long grain rice, which is in line with Supakornchuwong and Suwannaporn (2012) and Mintel (2014). Nonfrequent rice eaters were not keen on rice, as they had grown up with traditional British meals in which rice is not a significant component. Mature adult (38 years and older) non-frequent rice eaters consumed rice occasionally, during social gatherings and eating out occasions, but had considered it and decided not have it as a regular alternative to potatoes or pasta due to convenience of cooking and meal combinations, whereas young adult non-frequent rice eaters had not given it consideration.

The rice types that all UK participants were most familiar with were Basmati and long-grain rices. The preferred form was non-sticky separated grains, which usually accompanied stew/ casserole type dishes. These two rices were perceived to be 'easy to eat' and 'quick to cook', which might reflect the influence of mass advertisement of the leading RTE rice brands such as Uncle Ben's (Suwannaporn et $a l ., 2008)$. These views, influenced by repeated exposure to rice cooking and eating information, may encourage consumers to try cooking with the two familiar rice grains as an alternative to RTE rice that costs up to 6 times more per portion.

\section{$>$ Figure $2 \quad>$}

The perceptions of ease of eating were related to rice texture and compatibility in terms of mixing with other foods. It was clear from both genders and age groups that when consuming rice at home with family on a weekly basis, the UK consumers preferred to cook from rice grain rather than use an RTE rice or microwavable pouch product because of the cost difference.

Unpolished rice was felt to take a longer cooking time than white rice by both unfamiliar and familiar participants based on their knowledge and experience with long grain brown rice. For young adults who were not frequent rice eaters, the complexity of rice cooking was also a barrier to switching whereas the non-frequent rice eaters of mature participants did not view cooking time as a negative factor. They 
310 however required clear cooking instructions and were unwilling to experiment with 311 the cooking.

\subsubsection{Perceived quality indicators of cooked rice}

314 Consumer familiarity with rice was found to influence preferred rice textural 315 quality. The texture of fluffiness normally found in long grain basmati rice was 316 perceived to be good texture, with separated, non-sticky and light grains. This is in 317 contrast to the three Jasmine rice samples (a milled Jasmine Laila brand, two 318 unpolished black Jasmine samples (MNS) cooked with different cooking ratios of rice 319 to water) which were perceived and classified as Thai sticky rice. The research 320 samples unpolished pigmented MNS were opined to be too sticky compared with the 321 milled Jasmine sample (Laila) by the majority of participants in the four groups. 322 However, a few young male participants preferred sticky rice for eating on its own or 323 as a snack while young females did not like the sticky texture. The texture of Thai 324 unpolished pigmented rice MNS was also felt to be unpleasant while chewing because 325 of its hard bitty skin with gluey softness inside, particularly by adult females who 326 were responsible for household cooking. Interestingly, four younger participants of 327 both genders suggested the chewy gluey bits on Thai unpolished pigmented rice to be 328 a healthy characteristic, quite similar to what they perceived from commercial 329 unpolished rice.

330 The exemplars of Thai unpolished pigmented rice (MNS) presented in the 331 groups with two different cooking ratios of rice and water, were perceived to have 332 unique and strong odours, and described in terms such as mushroomy and nutty. The 333 strong odours were perceived positively by both age groups. The "fresh bean" odour 334 in the MNS rice particularly perceived by older adults to be an 'expensive and subtle' 335 smell, also referred to as an aromatic and unique odour by other participants. Dry 336 aftertaste was negatively perceived in Thai unpolished pigmented rice. Because 337 pigmented rice presented strong flavours, the participants suggested that the rice 338 should be consumed alongside other complimentary strong flavoured dishes like 339 casseroles to harmonise the strength of flavour, or use in salad dish to be a main 340 element dominating flavour of the dish.

The focus groups also reflected 'stage-of-life' effects showing differences 343 grain, while nobody from the other group ever mentioned the shelf-life of the grain 344 products. Cooking instructions were not key for mature rice-familiar adults as they 345 were experienced in cooking and had an understanding of how to obtain the right rice 346 texture to match their preferences, which was not the case with young adults. 
348

349

350

351

352

353

354

355

356

357

358

359

360

361

362

363

364

365

366

367

368

369

370

371

372

373

374

375

376

377

378

379

380

381

382

383

384

385

3.2 Sensory Descriptive Analysis - Flash Profile (FP)

\subsubsection{Generating rice sensory attributes}

The UK FP delivered 33 distinctive sensory characteristics, of which 19 attributes were mentioned by the majority of the panellists whereas the Thai FP resulted in 74 different attributes, with 12 being most frequently used (Table 1). Most of the UK FP descriptors were consensual. They captured the distinctive dominant characteristics of the rice samples well, such as smoky odour and savoury flavour. The variation of descriptors from UK panel was lower than in the Thai FP panel. A lack of exposure to the researched rice samples could well have led to a limitation in locating a greater diversity of sensory descriptors

$>$ Table $1>>$

The UK sensory profile of the Thai unpolished pigmented rice was predominantly perceived in the dimension of texture (e.g. first-bite hardness, smoothie mouthfeel, starchiness, stickiness, dry aftertaste, and residual aftertaste (bits)) when compared with the milled rices as shown in FP GPA results (Figure 3 (A and B)). Notably, this output could be influenced by the bran layer and familiarity of the panellists with Basmati and long grain rice texture as opposed to perceived stickiness of the Thai rice.

Both sensory profiles demonstrated similar categories of aroma and flavour, such as smoky, earthy, vanilla, sweet, and savoury from the UK panel and burnt, soil, earth, popcorn, steamed peanut, pandanus from Thai panel. The Thai odour descriptors included out-of-culture food aromas such as popcorn, berry, chocolate in an attempt to describe the sensory characteristics beyond what they were used to (e.g. steamed sticky rice, rice straw, old rice). In addition, the popcorn aroma especially perceived from the Thai rice types (including J, MNS and HNU), has previously been reported to be related to the 2-Acetyl-pyrroline compound found in aromatic and black rices (Yang et al., 2008 and Yang et al., 2010).

\subsubsection{Flash profiling of the unpolished pigmented rice samples}

Flash profiles of the 10 cooked rice samples demonstrated similarities as well as differences as evaluated by both panels. The GPA biplots of the FP results from UK panel (Figure 3) and Thai panel (Figure 4) provide a pictorial representation, which we summarise below. In terms of sensory profiling results where the magnitude of sensory attribute intensities were measured by ranked data in the FP, both GPA results on the first (F1) and second (F2) dimensions display clear clusters of rice samples (Figures 3B and 4B). 
386

387

388

389

390

391

392

393

394

395

396

397

398

399

400

401

402

403

404

405

406

407

408

409

410

411

412

413

414

415

416

417

418

419

420

421

422

423

424

425

Figure 3 shows the UK GPA result, the biplot (F1-F2) explains $47.69 \%$ of the total variance of this UK FP data set. The main discriminating sensory attributes of UK GPA, such as overall soft texture, colour (darkness), glossiness, first bite, sticky texture, saltiness, earthy flavour, sweet odour, musty odour, smoky aftertaste, dry aftertaste and bits-aftertaste, are seen in Figure 3 to have separated the milled rices B and $\mathrm{J}$ from the 4 unpolished pigmented rices (MNS, HNU, SYP and NLL). Sweet and musty odours are dominant in J rice. MNS and HNU profiles from three evaluations (3 replications of the set of 10 rice samples) were perceived to be close to each other on the basis of colour (darkness), first bite texture, salty flavour, earthy flavour, bits aftertaste and smoky aftertaste (Figure 3). The high salty ranked level perceived from these two rices requires more investigation as it could be a confusable effects from savoury flavour perceived by UK panellists but none from the Thais. SYP dominant characteristic is dry appearance as contrast to glossiness and sticky look perceived from NLL (Figure 3A). SYP samples cooked by two different methods were perceived quite similarly (Figure $3 \mathrm{~B}$ ). The mixed rice samples HNU-J and HNU-B were closely perceived and well differentiated from HNU by lesser intensity of first bite, saltiness and smoky aftertaste (Figure 3 and correlation configuration data from individual panellists - data not shown).

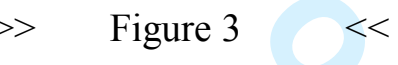

\section{$\gg \quad$ Figure 4}

Thai FP results analysed by GPA biplot are shown in Figure 4 with $66.87 \%$ of total variance explained by the first two factors F1 and F2). The higher percent of variance explained by the first two GPA factors refers to higher agreement in terms of data ranking on the FP product attributes among Thai panellists. Thai GPA biplot results (Figures 4A and 4B) demonstrate that the unfamiliar B rice was perceived to be 'slim' and to contain less pandanus odour and flavour when compared to the familiar J rice. Darkness of colour, mixed berry/ popcorn flavour, sticky texture (Thai $\mathrm{FP}$ ) increased from milled rices ( $\mathrm{J}$ and $\mathrm{B}$ ), mixed rices (HNU-J, HNU-B and NLL-J) and highest in the three unpolished pigmented rices (MNS, HNU and NLL). MNS and $\mathrm{HNU}$ are perceived quite similar in terms of black colour, hard and brittle texture, and mixed berry/ popcorn flavour. The colour and hard texture are dominant characteristic of these two rices as agreed by both GPA results. NLL is unique with the glossiness and sticky look perceived from both panels, plus high mixed berry/ popcorn flavour and sweet aftertaste perceived by Thais. The SYP positions (based on the panel perceived intensities) are at the middle due to its red pigment, rice straw odour and softer texture compared to the other three unpolished pigmented rices.

As compared to milled white rice, the dominant textural characteristics of unpolished pigmented rice have been identified to be grain intactness, fluffiness, 
426 firmness, stickiness and chewiness in previous studies. Pigmented rice flavours from 427 the FP results from this research were described as having high intensity of smoky, 428 earthy/mushroomy, sweet, woody, earthy, cooked rice, starch-like odours, in 429 agreement with Yau and Lui (1999), Yang et al. (2008), and Shobana et al. (2011). 430 The discriminating aromas of the unpolished pigmented rice, when tested against 431 milled aromatic rice types (including Basmati and Jasmine rice) have previously been 432 reported to be high hay-like and barny aromas (Limpawattana and Shewfelt, 2010) 433 whereas earthy/ mushroomy, pandanus, mixed berry/ popcorn and rice straw odour 434 were identified in this study.

Both the Thai and UK FP panels used in this study had previous experience and training with sensory QDA methods with a range of food products, and were hence termed 'skilled' panels. The levels of familiarity with respect to the rice samples were different between the two country groups however. The Thai FP panel were not familiar with two of the rice types - Basmati and MNS, with the first rice being imported and the second only grown in specific areas of the country and not nationally available. Whereas majority of the UK FP panel was familiar with Basmati rice, although a few had some minimal experience with wild rice and 'sticky' Jasmine rice before participating in the research.

The effects of familiarity with the test product in sensory profiling have been discussed much in previous literature. Liu et al. (2016) suggested that knowledge and experience of the products play a positive role in spanning the sensory space and yield high repeatability. This is consistent with earlier findings that the repeatability of rapid methods is positively affected by familiarity (Ares and Varela, 2014). However, it does not seem to be the case in this study as high repeatability is evidently seen in high RV coefficients between three repeated sessions from both Thai (0.987) and UK (0.933) panels. Although the Thai FP RV is higher but not significantly different from the UK FP RV $(\mathrm{p}>0.05)$.

In terms of discrimination performance, Figures 3 and 4 show that three unpolished pigmented rices SYP, MNS and HNU were less discriminated by the UK panel as compared to Thai panel. The influence of product familiarity appears to be reflected in smaller sensory space as shown in the first two GPA factors (Figure 3B). The UK F1 and F2 dimensions capture $47.69 \%$ of the total variance explained whereas Thai F1 and F2 present $66.87 \%$ variance (Figure 4B). This is in line with Giacalone et al. (2013) and Torri et al. (2013) who conclude that familiarity with the product leads to a better discrimination performance in rapid sensory profiling tasks.

\section{Conclusion \\ Healthy eating trends in the UK and other Western nations provide a potential opportunity for the development and export of unpolished pigmented rice from rice exporting countries such as Thailand. In this research, we have attempted to improve}


466 understanding of how unpolished pigmented rice is perceived by UK consumers, 467 investigating whether a lack of familiarity may differentiate the perceived sensory profiles, and hence perceived quality of the Thai unpolished pigmented rice.

Our focus group results point to a broad scope for positioning unpolished rice as an alternative to other starchy food sources (potatoes, pasta, and bread) that is perceived to prolong satiation (fulfilment) for young adults. The majority of young adult participants specified shorter cooking time to be part of their rice quality and convenience criteria. Mature-adults of unfamiliar rice eater group require clear cooking instructions and alternative recipes made available on the packaging. The perception of healthiness is attributed to chewy texture by a small proportion of the young adults. Speciality aromatic characteristics are perceived to be a favourable aspect of Thai unpolished pigmented rice (MNS). However, shortcomings in other quality dimensions specified in the UK focus groups, such as ease of cooking, unfamiliar sticky texture and residual aftertaste, indicates there is a scope for further product and process development to position Thai unpolished pigmented rice in the UK and other export markets

In the FP sensory rapid profiling, we evaluated a set of 10 rice samples designed from 6 rice types. The UK Flash Profiling results are in line with those from the focus groups in that TUPR is associated with strong and unique flavours (e.g., sweet and earthy flavours). Their dominant textural attributes in the form of bittiness and stickiness emerged in both methods, and these attributes were shown to be perceived as negative ones in the focus group results. Comparative results across the UK and Thailand suggest that, a lack of familiarity with unpolished pigmented rice in the UK may be impacting consumer perception with respect to quality indicators (e.g. by focusing on specific attributes such as unfamiliar textural characteristics). The negative sensory characteristics concerning textural and aftertaste qualities in TUPR as uncovered by this study could be improved by developing appropriate grain pretreatment and milling procedures.

The cooking methods as were experimented with in this research do not reveal major impact of cooking on sensory profiles, whereas experimentation with mixtures of rice reveals clearly distinctive characteristics. Thus our results suggest that the sensory uniqueness of each rice could be used to design rice mixtures to create innovative rice products.

As global demand for high quality rice has increased, Calingacion et al., (2014) have suggested that dominant sensory quality as objectively measured in rice based on several international standards such as length and shape of the grain, amylose content, gel consistency, gelatinisation temperature and aroma, are not sufficiently to evaluate the market quality of rice. The perceived sensory attributes derived from this study could assist in identifying the uniqueness of individual Thai unpolished pigmented rice types in order to establish rice identity claims (for geographic indication, intellectual property etc.), to indicate sensory quality traits for 
507 use in breeding, to investigate the effects of cooking conditions and methods, to

508 control quality of the rice, and to position Thai pigmented rice in the global market.

509

510

\section{References}

Addinsoft/ XLSTAT. (2016), "Data Analysis and Statistical Solution for 512 Microsoft Excel”, XLSTAT, Paris, France.

513 Ares, G. and Varela, P. (2014), "Comparison of novel methodologies for 514 sensory characterization”, in Varela, P. and Ares, G. (Eds.), Novel techniques in 515 sensory characterization and consumer profiling, CRC Press, Boca Raton, pp. 365516389.

517 Bhattacharjee, P., Singhal, R.S. and Kulkarni, P.R. (2002), "Basmati rice: a 518 review", International Journal of Food Science and Technology, Vol. 37 No. 1, pp. 151912.

520 Boquin, M.M., Moskowitz, H.R., Donovan, M.S. and Lee, S-Y. (2014), 521 "Defining Perceptions of Picky Eating Obtained through Focus Groups and Conjoint 522 Analysis", Journal of Sensory Studies, Vol. 29 Issue 2, pp. 126-138.

Casey, M.A. and Krueger, R.A. (2000), "Focus Groups: A Practical Guide for Applied Research", Sage, Thousand Oaks, California.

Calingacion M, Laborte A, Nelson A, Resurreccion A, Concepcion J.C. , et al. (2014), "Diversity of Global Rice Markets and the Science Required for ConsumerTargeted Rice Breeding”, PLoS ONE 9(1): e85106. doi:10.1371/journal.pone.0085106.

529 CBI [Centre for the Promotion of Imports from developing countries], 530 Ministry of Foreign Affairs. (2016), "Exporting specialty rice varieties to Europe", 531 available at: https://www.cbi.eu/market-information/grains-pulses/specialty-rice532 varieties/ (accessed 24 December 2016).

533 Chaudhry, S. and Crick, D. (2005), "A case history of a 'successful' Asian 534 entrepreneur in the UK: Moni Varma of Veetee Rice Ltd", Wiley InterScience DOI: $53510.1002 /$ jsc.733.

Dehlholm, C., Brockhoff, B.P., Meinert, L., Aaslyng, D. M. and Bredie, Sorting, Partial Napping, Napping, Flash Profiling and conventional profiling", Food 539 Quality and Preference, Vol. 26, pp. 267-277.

540 EC [European Commission]. (2016), "Classifying rice for import and export", 541 available at: https://www.gov.uk/guidance/classifyingrice (accessed 22 October 542 2016). 
Edgar, C., Jeehyun, L., Soonsil, C. and Ashley E.M. (2012), "Development of a Lexicon for commercially Available Cabbage (Baechu) Kimchi", Journal of Sensory Studies, Vol. 27 Issue 6, pp. 511-518.

FSA [Food Standards Agency]. [2014].“Guidance on Temperature Control Legislation in the United Kingdom”, available at: https://www.food.gov.uk/businessindustry/guidancenotes/hygguid/tempcontrolguidanceuk (accessed 11 January 2015).

Giacalone, D., Machado, L. and Frøst, M.B. (2013), "Consumer-based product profiling: Application of partial napping ${ }^{\circledR}$ for sensory characterization of specialty beers by novices and experts", Journal of Food Products Marketing, Vol. 19, pp. 201218.

International Trade Centre (2014), "Trade maps: International Trade Statistics", available at: www.trademap.org/tradestat/Bilateral_TS.aspx (accessed 23 October 2014).

Khatoon, N. and Prakash, J. (2007), "Physico-chemical characteristics, cooking quality and sensory attributes of microwave cooked rice varieties", Food Science and Technology Research, Vol. 13 No. 1, pp. 35-40.

Kormonchai, P., Dhamvithee, P., Therdthai, N. and Channuan, W. (2010), "Characterization of 8 Thai commercial Jasmine rice brand: chemical, physicochemical, physical qualities relating with consumer liking score using preference mapping", Agricultural Science Journal, Vol. 41 No. 1, pp. 476-479.

Kushwaha, U.K.S. (2016), "Black Rice”, in Kushwaha, U.K.S. (Ed.), Black Rice: Research, History and Development, Springer International Publishing, Switzerland, pp. 21-47.

Lakshmi, S., Chakkaravarthi, A., Subramanian, R. and Singh, V. (2007), "Energy consumption in microwave cooking of rice and its comparison with other domestic appliances", Journal of Food Engineering, Vol. 78, pp. 715-722.

Lawless, H.T. and Heymann, H. (2010), "Sensory Evaluation of Food: Principles and Practices", second edition, Spinger, London.

Li, J., Han, W., Xu, J., Xiong, S. and Zhao, S. (2014), "Comparison of morphological changes and in vitro starch digestibility of rice cooked by microwave and conductive heating", Starch/Stärke, Vol. 66, pp. 549-557.

Limpawattana, M. and Shewfelt, R.L. (2010), "Flavor lexicon for sensory descriptive profiling of different rice types", Journal of Food Science, Vol. 75, pp. 199-205.

Liu, L., Guo, J., Zhang, R., Wei, Z., Deng, Y., Guo, J. and Zhang, M. (2015), "Effect of degree of milling on phenolic profiles and cellular antioxidant activity of whole brown rice", Food Chemistry, Vol. 185, pp. 318-325. 
580

581

582

583

584

585

586

587

588

589

590

591

592

593

594

595

596

597

598

599

600

601

602

603

604

605

606

607

608

609

610

611

612

613

614

615

Liu, J, Schou Gronbeck, M., Di Monaco, R., Giacalone, D. and Bredie, W.-L.P. (2016), "Performance of Flash Profile and Napping with and without training for describing small sensory differences in model wine", Food Quality and Preference, Vol. 48, pp. 41-49.

Mintel (2016), "Pasta, Rice and Noodles - UK - February 2016", available at: http://academic.mintel.com/display (accessed 23 November 2016).

Pramai, P. and Jiamyangyuen, S. (2016), "Chemometric classification of pigmented rice varieties based on antioxidative properties in relation to color", Songklanakarin J. Sci. Technol. Vol. 38 No. 5, pp. 463-472.

Rabiee, F. (2004). Focus-group interview and data analysis", Proceedings of the Nutrition Society, Vol. 63, pp. 655-660.

Renton, A. (2013), "Expand your rice repertoire", available at: https: //www. theguardian.com/lifeandstyle/2013/jun/20/expand-your-rice-repertoire (accessed 1 May 2017).

Schenker, S. (2012), "An overview of the role of rice in the UK diet", available at: http://eds.b.ebscohost.com/eds/pdfviewer/pdfviewer? sid=851904c2-

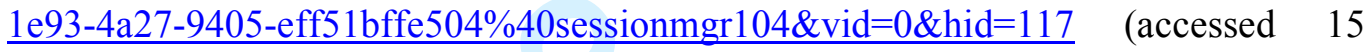
November 2016).

Sumczynski, D., Bubelova, Z. and Fišera, M. (2015), "Determination of chemical, insoluble dietary fibre, neutral-detergent fibre and in vitro digestibility in rice types commercialized in Czech markets", Journal of Food Composition and Analysis, Vol. 40, pp. 8-13.

Supakornchuwong, C. and Suwannaporn, P. (2012), "Attitudes toward rice compared with potatoes and pasta among British, French, Dutch and Belgian consumers", Journal of Sensory Studies, Vol. 27, pp. 71-77.

Suwannaporn, P. and Linnemann, A. (2008), "Rice-eating quality among consumers in different rice grain preference countries", Journal of Sensory Studies, Vol. 23, pp. 1-13.

Suwannaporn, P., Linnemann, A. and Chaveesuk, R. (2008), "Consumer preference mapping for rice product concepts", British Food Journal, Vol. 110 No. 6, pp. 595-606.

The rice association. (2017), "History", available at: http://www.riceassociation.org.uk/content/1/12/history.html (assessed 12 June 2017).

Torri, L., Dinnella, C., Recchia, A., Næs, T., Tuorila, H., and Monteleone, E. (2013), "Projective mapping for interpreting wine aroma as perceived by naïve and experienced assessors", Food Quality and Preference, Vol. 29, pp. 6-15. 
616 Valentin, D., Chollet, S., Lelievre, M. and Abdi, H. (2012), "Quick and dirty 617 but still pretty good: A review of new descriptive methods in food science", 618 International Journal of Food Science and Technology, Vol. 47, pp. 1563-1578.

619 Varela, P. and Ares, G. (2012), "Sensory profiling, the blurred line between 620 sensory and consumer science. A review of novel methods for product 621 characterization”, Food Quality and Preference, Vol. 48, pp. 893-908.

622 Yang, D.K., Lee, K.-S. and Kays, S. J. (2010), "Characterization and 623 discrimination of premium-quality, waxy, and black-pigmented rice based on odor624 active compounds", Journal of Food Science and Agricultural, Vol. 90, pp. 25956252601.

626 Yang, D.K., Shewfelt, R., Lee, K.-S. and Kays, S.J. (2008), “Comparison of 627 odour-active compounds from six distinctly different rice flavour types", Journal of 628 Agricultural and Food Chemistry, Vol. 56, pp. 2780-2787.

629 Yau, N.J.N. and Liu, T.T. (1999), "Instrumental and sensory analysis of 630 volatile aroma of cooked rice", Journal of Sensory Studies, Vol. 14 No. 2, pp. 209631233.

632 Yu, L., Turner, M.S., Fitzgerald, M., Stokes, J.R. and Witt, T. (2017), 633 "Review of the effects of different processing technologies on cooked and 634 convenience rice quality", Trends in Food Science \& Technology, Vol. 59, pp.124635138. 


\section{Dear Referee 1;}

Thank you for your positive feedback. We have addressed the referee's comments in red text below.

\section{REFEREE 1'S COMMENTS:}

Reviewer: 1

Recommendation: Minor revision then accept

Comments:

Just minor comments that you may want to consider. I think that this paper can be accepted after the latest recommended edits and clarifications are addressed:

1. line 49: Colour descriptors for rice grains don't include "black". these are typically described as purple Adjusted to 'light red to dark purple colours' (page 2, line 49)

2. line 72: Basmati is not a rice variety. There are different varieties described as basmati.

Adjusted to 'Among the well-known indica-type rices....' (page 2, line 70)

3. lines 91-97: This paragraph has greatly improved the clarity of the paper's objectives. Well done. Thank you, your previous comments were much appreciated.

4. line 150: Change "FDG" to "FGD".

Done (page 4, line 145)

5. lines 305-306: Please clarify who the familiar and the unfamiliar participants are. On first read, it seems that the familiar are the Thai and the unfamiliar are the UK participants. However, it seems that these lines pertain to the FGD, hence the confusion.

'Unfamiliar' mature participants is changed to 'non-frequent rice eaters' of mature participants (page 8, lines 300-301) 
Additional Questions:

1. Originality: Does the paper contain new and significant information adequate to justify publication?: Yes, the paper contains new and significant information that could lead to policy recommendations, particularly for exporting new rice products.

2. Relationship to Literature: Does the paper demonstrate an adequate understanding of the relevant literature in the field and cite an appropriate range of literature sources? Is any significant work ignored?: Yes, the survey of literature is adequate

3. Methodology: Is the paper's argument built on an appropriate base of theory, concepts, or other ideas? Has the research or equivalent intellectual work on which the paper is based been well designed? Are the methods employed appropriate?: Yes.

4. Results: Are results presented clearly and analysed appropriately? Do the conclusions adequately tie together the other elements of the paper?: Yes.

5. Implications for research, practice and/or society: Does the paper identify clearly any implications for research, practice and/or society? Does the paper bridge the gap between theory and practice? How can the research be used in practice (economic and commercial impact), in teaching, to influence public policy, in research (contributing to the body of knowledge)? What is the impact upon society (influencing public attitudes, affecting quality of life)? Are these implications consistent with the findings and conclusions of the paper?: Yes.

6. Quality of Communication: Does the paper clearly express its case, measured against the technical language of the field and the expected knowledge of the journal's readership? Has attention been paid to the clarity of expression and readability, such as sentence structure, jargon use, acronyms, etc.: The revised version of the paper has significantly clarified areas that were pointed out in the earlier review. The paper is now clear and easy to follow. 


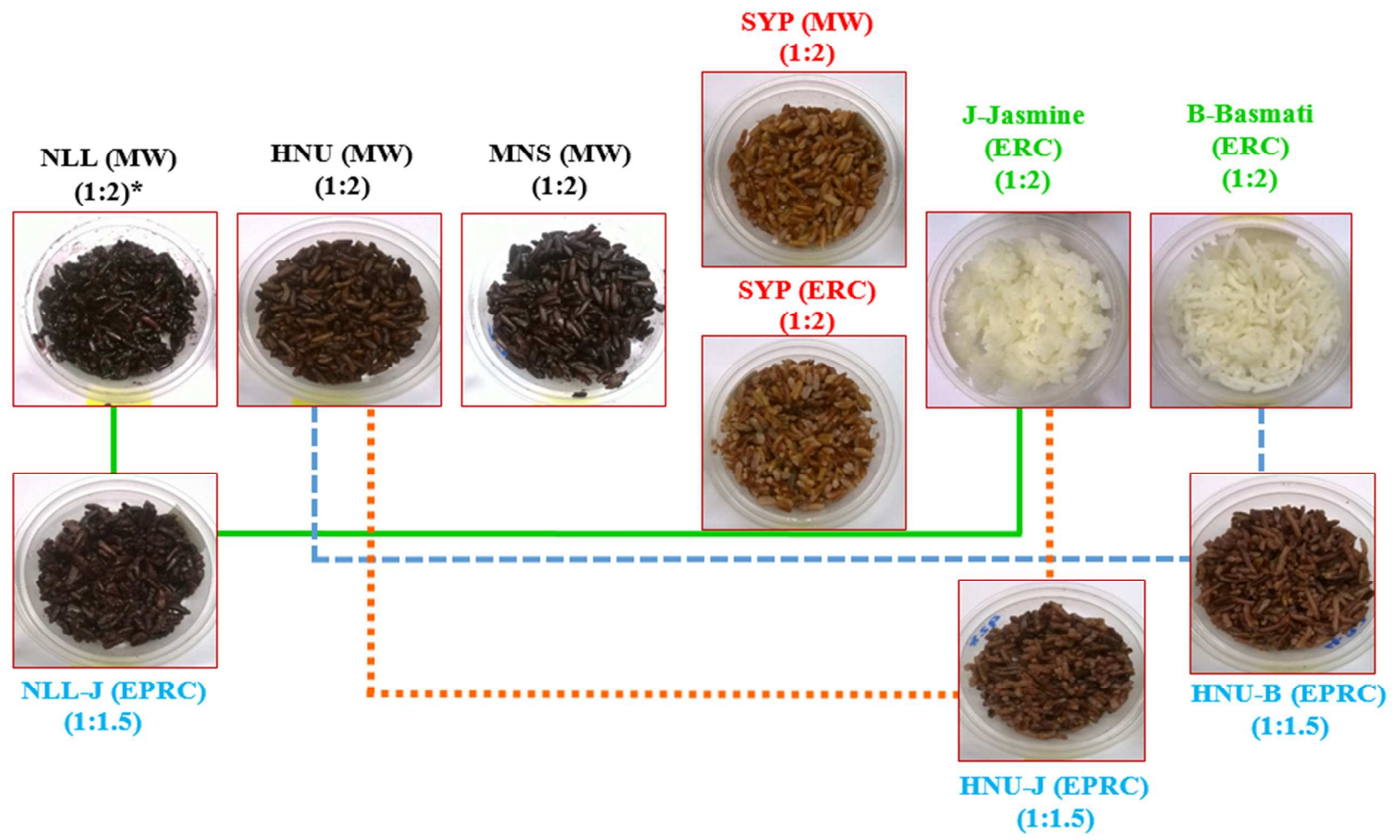

Figure 1 The 10 rice samples evaluated in Flash Profiling sessions (six rice types cooked by different methods; MW - Microwave Cooking, ERC - Electric Rice Cooker, EPRC - Electric Pressurising Rice Cooker).

* Rice to water ratio 


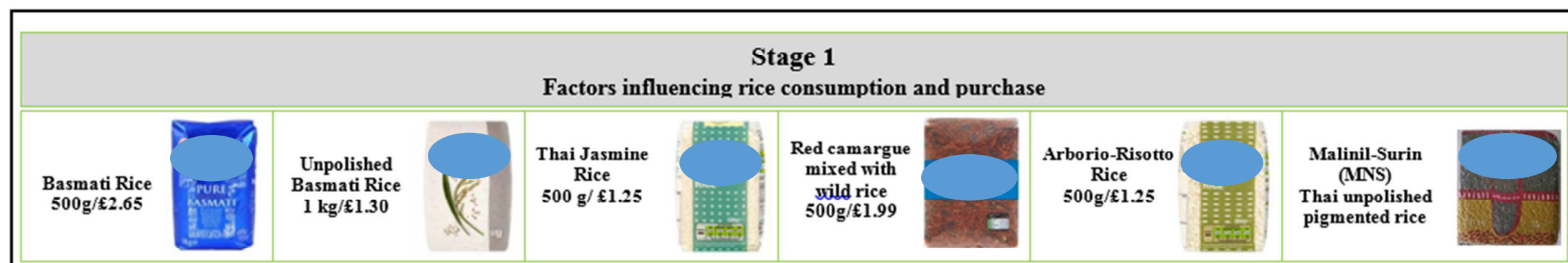

Purchase portion: Up to $1 \mathrm{~kg} /$ week

Rice eating habit: $2-3$ times $/$ week, $125 \mathrm{~g}$ for side dish, $250 \mathrm{~g}$ for main dish, prefer cooking from rice grain than RTE (cheaper), occasion consuming, Substitution of potato or pasta, cheaper, fulfilling, long shelf life

Cooking: with a pot, covering the lid, fluffing, with rinsing water, without rinsing water, longer cooking time (unpolished rice), difficult to cook (for right texture), need cooking instruction Perception on rice 'quality' in general: Ease to eat (separated grain, non-sticky texture, could conswome with many food), quick to cook, specialty rice (high price)

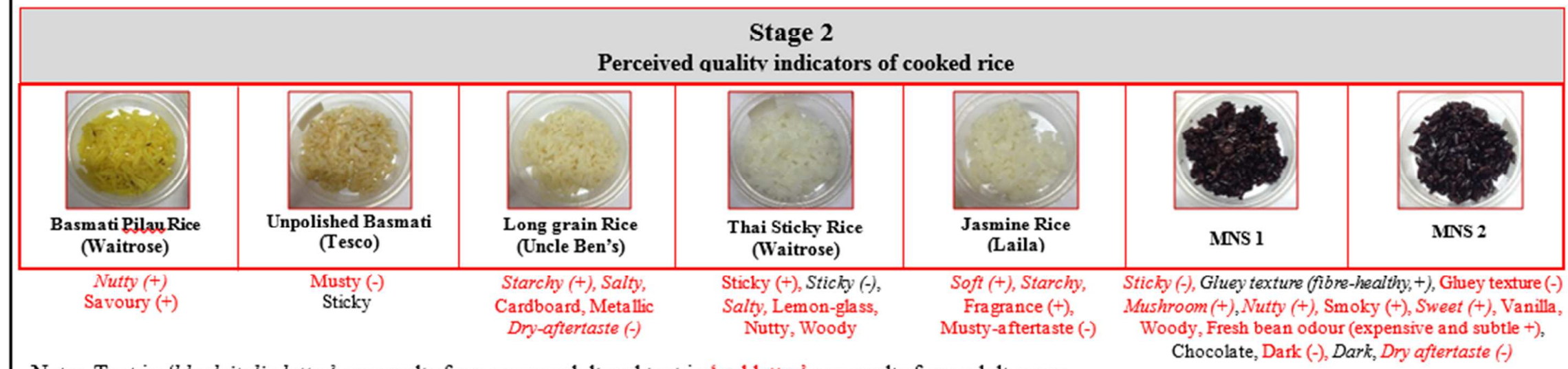

Note: Text in 'black italic letter' are results from young adult and text in 'red letter' are results from adult group. Text in 'red italic letter' are results from both groups.

Figure 2 Diagram of key qualities from focus group sessions 


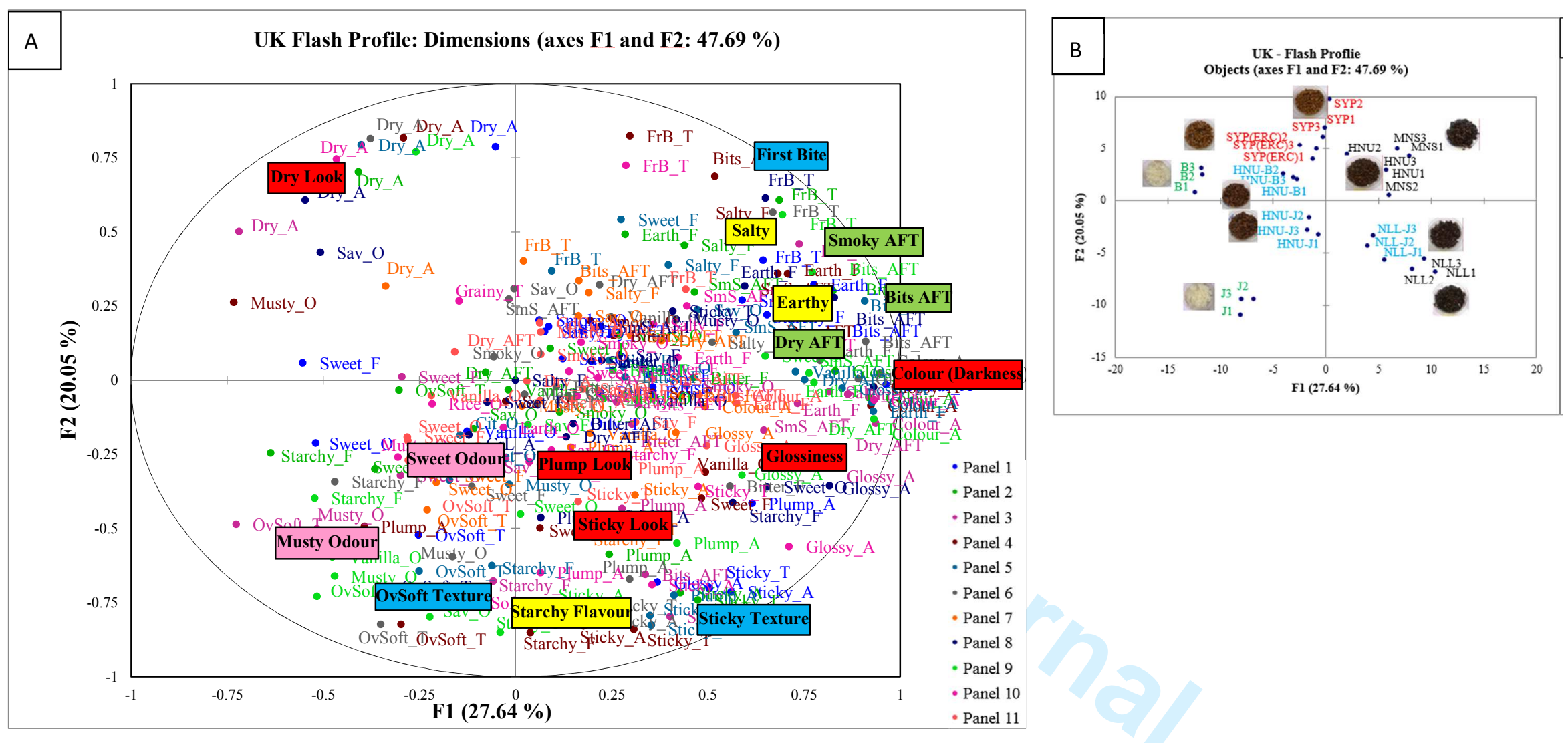

Figure 3 Attribute configuration of F1 - F2 of 10 rice samples obtained by GPA carried out on UK Flash profile data (the abbreviations of sensory attributes are presented in Table 1. Key attributes are highlighted in the square boxes, with red represents appearance, pink for odour, yellow for flavour, blue for texture and green for aftertaste attributes), and the product configuration of F1 - F2 (B) where the numbers 1, 2 and 3 represent replications of the FP. 


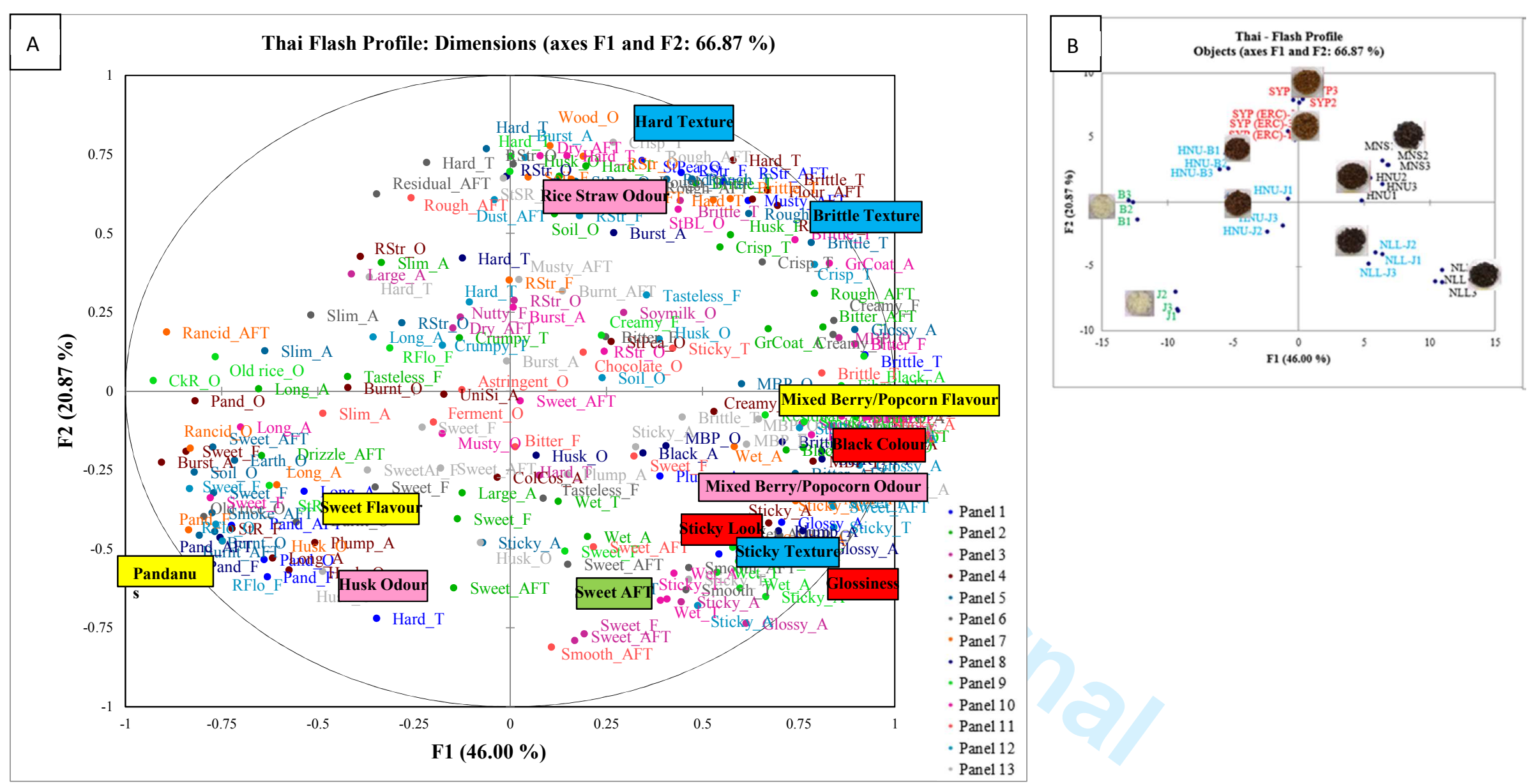

Figure 4 Attribute configuration (A) of F1 - F2 of 10 rice samples obtained by GPA carried out on Thai Flash profile data (the abbreviations of sensory attributes are presented in Table 1. Key attributes are highlighted in the square boxes, with red represents appearance, pink for odour, yellow for flavour, blue for texture and green for aftertaste attributes), and the product configuration of F1 - F2 (B) where the numbers 1,2 and 3 represent replications of the FP. 
Table 1 Sensory descriptors generated by UK and Thai panellists* in Flash profile sessions

\begin{tabular}{|c|c|c|c|c|c|c|c|}
\hline $\begin{array}{l}\text { Sensory descriptors } \\
\text { generated from UK panellists }\end{array}$ & $\begin{array}{l}\text { Frequency } \\
(\mathrm{n}=11)\end{array}$ & $\begin{array}{c}\text { Sensory descriptors } \\
\text { generated from Thai panellists }\end{array}$ & $\begin{array}{l}\text { Frequency } \\
(\mathrm{n}=13)\end{array}$ & $\begin{array}{c}\text { Sensory descriptors } \\
\text { generated from UK panellists }\end{array}$ & $\begin{array}{l}\text { Frequency } \\
(\mathrm{n}=11)\end{array}$ & $\begin{array}{c}\text { Sensory descriptors } \\
\text { generated from Thai panellists }\end{array}$ & $\begin{array}{l}\text { Frequency } \\
(\mathrm{n}=13)\end{array}$ \\
\hline Appearance (A) 7 descriptors & 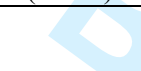 & $\begin{array}{c}\text { Appearance }(\mathrm{A}) 13 \\
\text { descriptors }\end{array}$ & & Odour $(\mathrm{O}) 9$ descriptors & & Odour $(\mathrm{O}) 20$ descriptors & \\
\hline Darkness (Colour)** & 11 & Black & 13 & Musty & 11 & Mixed Berry/ Popcorn (MBP) & 10 \\
\hline Dry look (Dry) & 11 & Sticky & 11 & Savoury (Sav) & 11 & Rice Straw/ Rice bran (RStr) & 8 \\
\hline Glossy & 11 & Glossy & 8 & Sweet & 11 & Husk & 7 \\
\hline Plump & 11 & Long & 6 & Vanilla & 11 & Steamed Sticky Rice (StSR) & 5 \\
\hline Sticky & 11 & Burst & 5 & Smoky & 10 & Burnt & 3 \\
\hline Grade of Colour (GdCo) & 1 & Plump & 5 & Citrus/Fragrance (Cit) & 1 & Soil/Dust (Soil) & 3 \\
\hline \multirow[t]{7}{*}{ Grain Length (GrL) } & 1 & Wet & 5 & Earthy/Woody (Earth) & 1 & Steamed Peanut (StPea) & 3 \\
\hline & & Slim & 4 & Meaty/Bacon/Smoky (Meat) & 1 & Chocolate & 2 \\
\hline & & Grain coating ( GrCoat) & 2 & Rice & 1 & Old rice & 2 \\
\hline & & Large size & 2 & & & Pandanus/Popcorn (Pand) & 2 \\
\hline & & Red & 1 & & & Astringent & 1 \\
\hline & & Colour Consistency (ColCons) & 1 & & & Cooked Rice (CkR) & 1 \\
\hline & & Uniformity of Size (UniSi) & 1 & & & Smell of earth after rain (Earth) & 1 \\
\hline Texture $(\mathrm{T})-7$ descriptors & & Texture $(\mathrm{T})-9$ descriptors & & & & Ferment & 1 \\
\hline First Bite hardness (FrB) & 11 & Hard & 12 & & & Rice Flour/Kanomkoh (RFlo) & 1 \\
\hline Overall Softness (OvSoft) & 11 & Brittle & 11 & & & Musty & 1 \\
\hline Sticky & 11 & Sticky & 9 & & & Rancid & 1 \\
\hline Grainy & 1 & Crisp & 4 & & & Soymilk & 1 \\
\hline Gritty & 1 & Wet & 4 & & & Steamed Banana Leaf (StBL) & 1 \\
\hline Oily & 1 & Rough & 2 & & & Wood & 1 \\
\hline \multirow[t]{3}{*}{ Smoothie Mouth Feel (SMF) } & 1 & Smooth & 2 & & & & \\
\hline & & Crumpy & 2 & & & & \\
\hline & & Creamy & 1 & & & & \\
\hline
\end{tabular}


Table 1 Sensory descriptors generated by UK and Thai panellists* in Flash profile sessions (continued)

\begin{tabular}{|c|c|c|c|c|c|c|c|}
\hline $\begin{array}{l}\text { Sensory descriptors } \\
\text { generated from UK panellists }\end{array}$ & $\begin{array}{l}\text { Frequency } \\
(\mathrm{n}=11)\end{array}$ & $\begin{array}{c}\text { Sensory descriptors } \\
\text { generated from Thai panellists }\end{array}$ & $\begin{array}{l}\text { Frequency } \\
\quad(n=13)\end{array}$ & $\begin{array}{c}\text { Sensory descriptors } \\
\text { generated from UK panellist }\end{array}$ & $\begin{array}{l}\text { Frequency } \\
(\mathrm{n}=11)\end{array}$ & $\begin{array}{c}\text { Sensory descriptors } \\
\text { generated from Thai panellists }\end{array}$ & $\begin{array}{l}\text { Frequency } \\
\quad(n=13)\end{array}$ \\
\hline Flavour (F) 6 descriptors & & Flavour $(\mathrm{F}) 13$ descriptors & & Aftertaste (AFT) 4 descriptors & & Aftertaste (AFT) 19 descriptors & \\
\hline Earthy/Mushroomy ( Earth) & 11 & Sweet & 11 & Smoky Smell (SmS) & 11 & Sweet & 8 \\
\hline Salty & 11 & Mixed Berry/ Popcorn (MBP) & 9 & Metallic feel (Dry) & 11 & Rough & 5 \\
\hline Starchy & 11 & Bitter & 4 & Physical residue (Bits) & 11 & Residual & 4 \\
\hline Sweet & 11 & Pandanus/Popcorn (Pand) & 3 & Bitter & 3 & Bitter & 3 \\
\hline Bitter & 10 & Rice Straw/ Rice Bran (RStr) & 3 & & & Burnt & 2 \\
\hline \multirow[t]{14}{*}{ Savoury/Umani (Sav) } & 10 & Bland $>(0)=2$ & 3 & & & Dry & 2 \\
\hline & & Creamy & 2 & & & Musty/Stale (Musty) & 2 \\
\hline & & Rice Flour/Kanomkoh (RFlo) & 2 & & & Pandanus/Popcorn (Pand) & 2 \\
\hline & & Steamed rice $(\mathrm{StR})$ & 2 & & & Smoky (Smoke AFT) & 2 \\
\hline & & Nutty & 1 & & & Smooth (Smooth AFT) & 2 \\
\hline & & Husk & 1 & & & Creamy & 1 \\
\hline & & Soil & 1 & & & Drizzle & 1 \\
\hline & & Sweet Aroma (SweetAr) & 1 & & & Dust & 1 \\
\hline & & & & & & Fibre & 1 \\
\hline & & & & & & Flour & 1 \\
\hline & & & & & & Rancid & 1 \\
\hline & & & & & & Rice Straw/ Rice bran (RStr) & 1 \\
\hline & & & & & & Steamed Sticky Rice (StSR) & 1 \\
\hline & & & & & & Mixed Berry/ Popcorn (MBP) & 1 \\
\hline
\end{tabular}

* The UK FP generated 33 descriptors and the Thai FP generated 74 descriptors in total. The data from UK FP and Thai FP were analysed by GPA (Addinsoft, 2016: XLSTAT, 2016) to identify the dominant sensory characteristics of the rice samples across the two panels. 